\title{
Relationship between Depression and Laryngopharyngeal Reflux
}

\author{
Young-Hoon Joo', Youn-Su Song ${ }^{1}$, and Chi-Un Pae ${ }^{2,3 凶}$ \\ 1Department of Otolaryngology-Head \& Neck Surgery, The Catholic University of Korea College of Medicine, Seoul, Republic of Korea \\ 2Department of Psychiatry, The Catholic University of Korea College of Medicine, Seoul, Republic of Korea \\ ${ }^{3}$ Department of Psychiatry and Behavioral Sciences, Duke University Medical Center, Durham, NC, USA
}

This study investigated the relationship between depression, somatization, anxiety, personality, and laryngopharyngeal reflux (LPR). We prospectively analyzed 231 patients with symptoms with LPR using the laryngopharyngeal reflux symptom index and the reflux finding score. Seventy nine (34.2\%) patients were diagnosed with LPR. A significant correlation was detected between the presence of LPR and

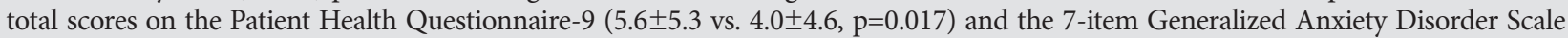
( $4.3 \pm 4.9$ vs. $3.0 \pm 4.5, \mathrm{p}=0.041)$. LPR was significantly more frequent in those with depression than in those without $(45.6 \%$ vs. $27.0 \%$, $\mathrm{p}=0.004$ ). A multivariate analysis confirmed a significant association between the presence of LPR and depression (odds ratio, 1.068; $95 \%$ confidence interval, 1.011-1.128; $\mathrm{p}=0.019$ ). Our preliminary results suggest that patients with LPR may need to be carefully evaluated for depression.

Psychiatry Investig 2017;14(2):226-229

Key Words Laryngopharyngeal reflux, Depression, Anxiety, Somatoform disorders, Personality.

\section{INTRODUCTION}

Laryngopharyngeal reflux (LPR) is retrograde movement of gastric contents into the larynx and pharynx leading to a variety of upper aerodigestive tract symptoms. It is estimated that $4-10 \%$ of patients presenting to otolaryngologists have LPR. ${ }^{1,2}$ Furthermore, $50-60 \%$ of chronic laryngitis cases and difficult-to-treat sore throats may be related to LPR. ${ }^{3}$

Many of the symptoms related to LPR are nonspecific, such as voice change, chronic throat clearing, chronic cough, globus pharyngeus, and dysphagia. Most patients complaining of these symptoms do not show specific abnormalities on a laryngeal examination. ${ }^{4}$ The most commonly reported physical findings of LPR on fiberoptic endoscopy are edema and erythema of the larynx. ${ }^{5,6}$ At least two studies have found laryngeal abnormalities in a healthy asymptomatic population. ${ }^{7}$ The lack of definite abnormal findings accounting for these symptoms and variability of the condition suggest the possibility of an associa-

Received: January 24, 2016 Revised: February 26, 2016

Accepted: April 4, 2016 Available online: October 13, 2016

$\triangle$ Correspondence: Chi-Un Pae, MD, PhD

Department of Psychiatry, Bucheon St. Mary's Hospital, College of Medicine, The Catholic University of Korea, 327 Sosa-ro, Wonmi-gu, Bucheon 14647, Republic of Korea

Tel: +82-32-340-7067, Fax: +82-32-340-2544, E-mail: pae@catholic.ac.kr

(a) This is an Open Access article distributed under the terms of the Creative Commons Attribution Non-Commercial License (http://creativecommons.org/licenses/bync/4.0) which permits unrestricted non-commercial use, distribution, and reproduction in any medium, provided the original work is properly cited. tion with psychological factors. ${ }^{8-11}$ These psychological factors may have an important role in the predisposition, initiation, progression, and aggravation of LPR symptoms. ${ }^{9-11}$

The present study investigated the associations between depression, somatization, and anxiety and the presence of LPR in a routine clinical practice to better understand the relationships between depression, somatization, anxiety, and LPR.

\section{METHODS}

\section{Subjects}

Patients with chronic laryngeal signs and symptoms suspected to be reflux-related and who visited the Department of Otolaryngology-HNS, the Catholic University of Korea between April, 2014 and June, 2015 were assessed for study eligibility. Principal inclusion criteria included age $\geq 20$ years, a clinical diagnosis of LPR, which was evaluated by medical history, a careful laryngoscopic examination, and a self-administered questionnaire. The institutional review board of Bucheon St. Mary's Hospital approved all protocols and the study design, and all patients gave written informed consent.

Laryngoscopy was performed by an otolaryngologist (YHJ) and interpreted by two independent otolaryngologists (YHJ and YSS). Reflux finding scores (RFS) were summed to determine the score for each of the following findings: subglottic edema $(0 / 2)$, vocal fold edema $(0 / 1 / 2 / 3 / 4)$, ventricular 
obliteration $(0 / 2 / 4)$, diffuse laryngeal edema $(0 / 1 / 2 / 3 / 4)$, erythema/hyperemia $(0 / 2 / 4)$, posterior commissure hypertrophy $(0 / 1 / 2 / 3 / 4)$, thick mucus $(0 / 2)$, and granuloma $(0 / 2)$. The reflux symptom index (RSI) is a self-administered nine-item questionnaire designed to assess various symptoms related to LPR (Table 1). Each item is rated on a scale from 0 (no problem) to 5 (severe problem), with a maximum total score of 45 , indicating the most severe symptoms. LPR was defined as a RFS $>7$ and a RSI score $>13.12,13$

\section{Rating scales}

This study used the following measures to investigate the associations between the presence of depression or somatization and symptom severity in patients with LPR. The Korean version of the Patient Health Questionnaire-9 (PHQ-9) for depression, the Patient Health Questionnaire-15 (PHQ-15) for somatization, the 7-item Generalized Anxiety Disorder Scale (GAD-7) for anxiety, and the 44-item Big Five Inventory (BFI) for personality traits. ${ }^{14-16}$ The criteria for depression (PHQ-9 $\geq 5$ ), anxiety (GAD-7 $\geq 5$ ), and somatization (PHQ-15 $\geq 10$ ) were defined as suggested by previous studies. ${ }^{14-16}$ The BFI personality traits are extraversion (talkative, assertive, and energetic); agreeableness (good-natured, cooperative, altruistic, and empathic); conscientiousness (orderly, responsible, and dependable); neuroticism (neurotic, easily upset, and not self-confident); and openness (open to experience, intellectual, imaginative, and independent-minded). The BFI consists of 44 items; higher scores represent higher levels of each personality trait. ${ }^{17}$

\section{Statistics}

The statistical analysis was performed using SPSS v. 16.0 (SPSS Inc., Chicago, IL, USA). The chi-square test, Fisher's exact test, multiple logistic regression analysis, multiple linear regression analysis, and correlation analysis were used, as appropriate, to detect significant associations among the distribution of categorical values. $\mathrm{P}$-values $<0.05$ were considered significant. Numeric data are expressed as means \pm standard deviations.

\section{RESULTS}

\section{Patient characteristics}

A total of 231 patients participated in the study [158 (68.4\%) women; mean age, 54.6 years; range, $20-78$ years], and 131 (56.7\%) had a RSI score $>13$, and 136 (58.9\%) had a RFS $>7$. Seventy-nine patients had significant RFS and RSI score, resulting in LPR prevalence of $34.2 \%$. No difference in LPR incidence was detected between men and women $(\mathrm{p}=0.076)$. Mean scores on the PHQ-9, PHQ-15, and GAD-7 were 4.6 \pm 4.9
[61.0\% normal to minimal depression ( $\mathrm{n}=141) ; 46.2 \%$ mild to severe depression $(n=90)], 6.2 \pm 4.5$ [19.5\% normal to minimal somatic symptoms $(\mathrm{n}=45) ; 80.5 \%$ low to severe somatic symptoms $(\mathrm{n}=186)]$, and $3.4 \pm 4.7$ [25.1\% normal to minimal anxiety $(n=58) ; 74.9 \%$ mild to severe anxiety $(n=173)]$, respectively.

\section{Relationships between LRP and depression, somatization, anxiety, and personality}

Significant correlations were detected between the presence of LPR and total scores on the PHQ-9 $(\mathrm{p}=0.017)$ and GAD-7 ( $\mathrm{p}=0.041$ ). Mean total scores on the PHQ-9 and GAD7 in cases with LPR were 5.6 \pm 5.3 and $4.3 \pm 4.9$, respectively, whereas those without LPR had mean total scores on the

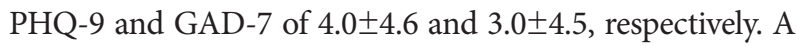
marginally significant correlation was observed between the presence of LPR and total PHQ-15 score ( $\mathrm{p}=0.051)$. The presence of LPR was significantly different between those with and without depression, as defined by total PHQ-9 score $(p=0.004)$. However, no differences in the presence of LPR were observed between those with and without somatization, anxiety, or personality traits (Table 1). A multivariate Cox regression analysis confirmed a significant association between the presence of LPR and the PHQ-9 (odds ratio, 1.068; 95\% confidence interval, 1.011-1.128; $\mathrm{p}=0.019$ ).

\section{DISCUSSION}

LPR-related symptoms are commonly presented to otolaryngologists. Some authors have reported that $10 \%$ of patients presenting have LPR. ${ }^{18}$ Kamani et al. ${ }^{19}$ estimated that the prevalence of LPR symptoms in the UK population was $34.4 \%$. Globus sensation, throat clearing, cough, and other nonspecific symptoms are different presentations that may be related to LPR. The most commonly reported physical findings of LPR on fiberoptic endoscopy are edema and erythema of the larynx. ${ }^{6,20}$ At least two studies have found that laryngeal abnormalities are detectable in the healthy asymptomatic population. $^{21,22}$ The inconsistent findings related to presentation of LPR and uncertainty of the etiological background of these presentations suggests a possible association between these presentations and psychological problems. ${ }^{23}$

Many studies have evaluated the psychological influence in patients with non-specific upper aerodigestive tract symptoms, particularly globus. Globus has been thought to be a definite hysterical symptom, as it is strongly associated with depressive illness responds well to antidepressant therapy. ${ }^{10}$ Park et al. $^{24}$ reported that patients with globus tended to have somatization regardless of LPR but patients without reflux reveal significantly higher scores on all other symptom dimen- 
Table 1. Correlations between depression, somatization, anxiety, and personality traits with laryngopharyngeal reflux status ( $N=231$ )

\begin{tabular}{|c|c|c|c|c|}
\hline \multirow{2}{*}{ Parameter } & \multirow{2}{*}{ Case } & \multicolumn{3}{|c|}{ Laryngopharyngeal reflux } \\
\hline & & Yes $(\mathrm{N}=79)$ & No $(\mathrm{N}=152)$ & p-value \\
\hline Age (years) & & $54.0 \pm 10.5$ & $55.0 \pm 10.2$ & 0.461 \\
\hline Gender (\%) & & & & 0.076 \\
\hline Male & 73 & 42.5 & 57.5 & \\
\hline Female & 158 & 30.4 & 69.6 & \\
\hline Depression (\%) & & & & $0.004^{*}$ \\
\hline Yes & 90 & 45.6 & 54.4 & \\
\hline No & 141 & 27.0 & 73.0 & \\
\hline Somatization (\%) & & & & 0.384 \\
\hline Yes & 45 & 40.0 & 60.0 & \\
\hline No & 186 & 32.8 & 67.2 & \\
\hline Anxiety (\%) & & & & 0.056 \\
\hline Yes & 58 & 44.8 & 55.2 & \\
\hline No & 173 & 30.6 & 69.4 & \\
\hline Extraversion (mean) & & $3.2 \pm 0.9$ & $3.1 \pm 0.8$ & 0.392 \\
\hline Agreeableness (mean) & & $3.7 \pm 0.7$ & $3.7 \pm 0.7$ & 0.827 \\
\hline Conscientiousness (mean) & & $4.0 \pm 0.7$ & $4.1 \pm 0.8$ & 0.546 \\
\hline Neuroticism (mean) & & $2.9 \pm 0.8$ & $3.1 \pm 0.9$ & 0.147 \\
\hline Openness (mean) & & $3.3 \pm 0.7$ & $3.2 \pm 0.8$ & 0.619 \\
\hline
\end{tabular}

*significant at $\mathrm{p}<0.05$

sions of the Symptom Checklist-90-Revised. Globus symptoms in men indicate a much more profound psychological problem than those in women with the same complaint. ${ }^{11}$ Barofsky et al. ${ }^{25}$ also observed a group of patients who complain of swallowing difficulties but who have normal pharyngeal function following radiological and psychological evaluations but have clinically significant psychological characteristics. However, studies investigating the relationship between LPR and psychological factors are rare. A recent cohort study found that one-third of patients with LPR suffer from anxiety and significantly reduced social activities compared with those in controls. ${ }^{26}$ However, in other studies, patients with LPR did not demonstrate any psychological distress. ${ }^{27,28} \mathrm{Me}-$ sallam et al. ${ }^{28}$ reported that the psychological background of patients with LPR does not affect the patients' self-perception of their reflux-related problem. Chronic laryngeal signs and symptoms associated with gastroesophageal reflux (GERD) are often referred to as LPR or reflux laryngitis. LPR is an extraesophageal variant of GERD, because the main symptomatic region involves the laryngopharynx. The relationship between psychological distress and GERD is complex and poorly defined. GERD may contribute to psychological distress, and in fact, psychological distress may contribute more significantly to poor quality of life than do symptoms. In a meta-analysis by El-Serag, persistent GERD symptoms despite medical treatment were associated with decreased psychological and physical well-being. ${ }^{29}$ van der Velden et al. ${ }^{30}$ found that subjects with residual GERD symptoms had an odds ratio of 2.8 and 3.2 for anxiety and depression, respectively.

We provide evidence suggesting that a significant portion of patients with LPR may struggle with symptoms of depression during the clinical course of their disorder. In the present study, the mild to severe depression rate was $46.2 \%$ (90 of 231). In addition, 41 (51.9\%) of our 79 patients with LPR had depression, whereas only 49 (32.2\%) of the 152 patients without LPR had depression. This finding suggests that patients with LPR may suffer from a broad range of clinical manifestations of depression. These are the first data supporting a substantial influence of depression on LPR. These results may help clinicians understand the role of depression as a potential moderator in the clinical manifestation of LPR.

The limitations of this study include the following. First, the study cohort was small, leading to large standard deviations. Second, we did not consider other psychiatric comorbidities. Third, no formal diagnosis of depression was made by structured interview. Future studies employing prospective, randomized methods to examine the psychological problems in patients with LPR are warranted.

In conclusion, the present study preliminarily demonstrates that clinicians may need to carefully evaluate depression to properly management patients with LPR. Subsequent adequately-powered studies with a better design will be crucial to validate and support our preliminary findings.

\section{Acknowledgments}

Acknowledgment: This study was supported by a grant from the Korean 
Health Technology R\&D Project, Ministry of Health \& Welfare, Republic of Korea (HI12C0003).

\section{REFERENCES}

1. Katz PO. State of the art: extraesophageal manifestations of gastroesophageal reflux disease. Rev Gastroenterol Disord 2005;5:126-134.

2. Vaezi MF. Extraesophageal manifestations of gastroesophageal reflux disease. Clin Cornerstone 2003;5:32-38.

3. Hicks DM, Ours TM, Abelson TI, Vaezi MF, Richter JE. The prevalence of hypopharyngeal findings associated with gastroesophageal reflux in normal volunteers. J Voice 2002;16:564-579.

4. Pratt LW, Tobin WH, Gallagher RA. Globus hystericus-office evaluation by psychological testing with the MMPI. Laryngoscope 1976;86: 1540-1551.

5. Ahmed TF, Khandwala F, Abelson TI, Hicks DM, Richter JE, Milstein $\mathrm{C}$, et al. Chronic laryngitis associated with gastroesophageal reflux: prospective assessment of differences in practice patterns between gastroenterologists and ENT physicians. Am J Gastroenterol 2006;101:470478

6. Qadeer MA, Swoger J, Milstein C, Hicks DM, Ponsky J, Richter JE, et al. Correlation between symptoms and laryngeal signs in laryngopharyngeal reflux. Laryngoscope 2005;115:1947-1952.

7. Hicks DM, Ours TM, Abelson TI, Vaezi MF, Richter JE. The prevalence of hypopharynx findings associated with gastroesophageal reflux in normal volunteers. J Voice 2002;16:564-579.

8. Mirza N, Ruiz C, Baum ED, Staab JP. The prevalence of major psychiatric pathologies in patients with voice disorders. Ear Nose Throat J 2003;82:808-814.

9. Bhatia MS, Chandra R, Vaid L. Psychogenic cough: a profile of 32 cases. Int J Psychiatry Med 2002;32:353-360.

10. Cybulska EM. Globus hystericus--a somatic symptom of depression? The role of electroconvulsive therapy and antidepressants. Psychosom Med 1997;59:67-69.

11. Pratt LW, Tobin WH, Gallagher RA. Globus hystericus -- office evaluation by phychological testing with the MMPI. Laryngoscope 1976; 86:1540-1551.

12. Belafsky PC, Postma GN, Koufman JA. Validity and reliability of the reflux symptom index (RSI). J Voice 2002;16:274-277.

13. Belafsky PC, Postma GN, Koufman JA. The validity and reliability of the reflux finding score (RFS). Laryngoscope 2001;111:1313-1317.

14. Han C, Jo SA, Kwak JH, Pae CU, Steffens D, Jo I, et al. Validation of the Patient Health Questionnaire-9 Korean version in the elderly population: the Ansan Geriatric Study. Compr Psychiatry 2008;49:218-223.

15. Han C, Pae CU, Patkar AA, Masand PS, Kim KW, Joe SH, et al. Psychometric properties of the Patient Health Questionnaire-15 (PHQ15) for measuring the somatic symptoms of psychiatric outpatients. Psychosomatics 2009;50:580-585.
16. Spitzer RL, Kroenke K, Williams JB, Löwe B. A brief measure for assessing generalized anxiety disorder: the GAD-7. Arch Intern Med 2006; 166:1092-1097.

17. John OP, Srivastata S. The Big Five Trait Taxonomy: History, Measurement, and Theoretical Perspectives. In: Pervin LA, John OP, Editors. Handbook of Personality. 2nd Ed. New York: Guilford Press, 1999, p. 102-138.

18. Koufman JA, Aviv JE, Casiano RR, Shaw GY. Laryngopharyngeal reflux: position statement of the committee on speech, voice, and swallowing disorders of the American Academy of Otolaryngology-Head and Neck Surgery. Otolaryngol Head Neck Med Surg 2002;127:32-35.

19. Kamani T, Penney S, Mitra I, Pothula V. The prevalence of laryngopharyngeal reflux in the English population. Eur Arch Otorhinolaryngol 2012;269:2219-2225.

20. Ahmed TF, Khandwala F, Abelson TI, Hicks DM, Richter JE, Milstein C, et al. Chronic laryngitis associated with gastroesophageal reflux: prospective assessment of differences in practice patterns between gastroenterologists and ENT physicians. Am J Gastroenterol 2006;101: 470-478.

21. Hicks DM, Ours TM, Abelson TI, Vaezi MF, Richter JE. The prevalence of hypopharynx findings associated with gastroesophageal reflux in normal volunteers. J Voice 2002;16:564-579.

22. Milstein CF, Charbel S, Hicks DM, Abelson TI, Richter JE, VaeziMF. Prevalence of laryngeal irritation signs associated with reflux in asymptomatic volunteers: impact of endoscopic technique (rigid vs. flexible laryngoscope). Laryngoscope 2005;115:2256-2261.

23. Oyer SL, Anderson LC, Halum SL. Influence of anxiety and depression on the predictive value of the reflux symptom index. Ann Otol Rhinol Laryngol 2009;118:687-692.

24. Park KH, Choi SM, Kwon SU, Yoon SW, Kim SU. Diagnosis of laryngopharyngeal reflux among globus patients. Otolaryngol Head Neck Surg 2006;134:81-85.

25. Barofsky I, Fontaine KR. Do psychogenic dysphagia patients have an eating disorder? Dysphagia 1998;13:24-27.

26. Siupsinskiene N, Adamonis K, Toohill RJ. Quality of life in laryngopharyngeal reflux patients. Laryngoscope 2007;117:480-484.

27. Shin KS, Tae K, Jeong JH, Jeong SW, Kim KR, Park CW, et al. The role of psychological distress in laryngopharyngeal reflux patients: a prospective questionnaire study. Clin Otolaryngol 2010;35:25-30.

28. Mesallam TA, Shoeib RM, Farahat M, Kaddah FA, Malki KH. Studying the Psychological Profile of Patients with Laryngopharyngeal Reflux. Folia Phoniatr Logop 2015;67:51-56.

29. El-Serag H, Becher A, Jones R. Systematic review: persistent reflux symptoms on proton pump inhibitor therapy in primary care and community studies. Aliment Pharmacol Ther 2010;32:720-737.

30. van der Velden AW, deWit NJ, Quartero AO, Grobbee DE, Numans ME. Maintenance treatment for GERD: residual symptoms are associated with psychological distress. Digestion 2008;77:207-213. 